(2) Open Access Full Text Article

\title{
Impact of selective platelet inhibition in reducing cardiovascular risk - role of vorapaxar
}

\author{
This article was published in the following Dove Press journal: \\ Vascular Health and Risk Management \\ 14 June 2016 \\ Number of times this article has been viewed
}

\section{Judy WM Cheng}

Department of Pharmacy Practice, MCPHS University, Boston, MA, USA
Correspondence: Judy WM Cheng Department of Pharmacy Practice, MCPHS University, 179 Longwood Avenue, Boston, MA 02115-5896, USA Tel + I 6177322868

Fax +I 6177322244

Email judy.cheng@mcphs.edu
Abstract: This article reviews the pharmacology, clinical efficacy, and safety of vorapaxar in reducing cardiovascular risk. Vorapaxar is a tricyclic himbacine-derived reversible inhibitor of platelet surface protease activator receptor-1, which prevents thrombin from activating platelets. Two Phase III clinical trials and multiple subanalyses from the two trials with vorapaxar have been published. In patients with recent acute coronary syndrome, vorapaxar, when added to standard therapy, did not reduce the composite cardiovascular end point. In contrary, in a study of secondary prevention for patients with cardiovascular diseases, vorapaxar reduced the risk of cardiovascular death or ischemic events (myocardial infarction, stroke) in patients with stable atherosclerosis who were receiving standard therapy. Vorapaxar is approved in the US for use with aspirin and/or clopidogrel in the secondary prevention of thrombogenic cardiovascular events in stable patients with peripheral arterial disease or a history of myocardial infarction. Vorapaxar increases risk of bleeding and is contraindicated in patients with previous cerebrovascular events. It is essential to balance individual patient's bleeding risk to any further cardiovascular benefits that they may get. Future investigation is also needed to evaluate use of vorapaxar with newer antiplatelet agents such as ticagrelor and cangrelor, as well as its role as monotherapy.

Keywords: vorapaxar, protease activator receptor-1 antagonist, atherosclerotic disease

\section{Introduction}

Cardiovascular diseases, including coronary artery disease (CAD), cerebrovascular disease, peripheral arterial disease (PAD), are leading causes of morbidity and mortality worldwide. ${ }^{1}$ Atherosclerosis leading to thrombotic occlusion of arteries is the main pathophysiologic mechanism of these events. Platelets produce vasoactive and prothrombotic mediators in response to vascular injury, which leads to thrombus formation. $^{2}$

Antiplatelet drug therapies play an important role in cardiovascular disease management. Aspirin (cyclooxygenase inhibitor) has been well established for primary and secondary prevention of cardiovascular diseases. ${ }^{3,4}$ Dual antiplatelet therapy (DAPT) with aspirin and $\mathrm{P}_{2} \mathrm{Y}_{12}$ receptor antagonists, such as clopidogrel, prasugrel, and ticagrelor, has been evaluated to benefit patients with acute coronary syndrome (ACS) and/or those undergoing percutaneous coronary intervention (PCI). ${ }^{3-10}$ More recently, the first intravenous $\mathrm{P}_{12} \mathrm{Y}_{12}$ inhibitor, cangrelor, has also become available for use in patients undergoing PCI. Cangrelor provides quick onset of antiplatelet effects and has been demonstrated to significantly reduce the rate of ischemic events, including stent thrombosis, when used during PCI. ${ }^{11}$ Intravenous glycoprotein IIb/IIIa 
inhibitors have also been established to be used in certain high-risk patients undergoing PCI. ${ }^{3,4}$ The development of newer antiplatelet agents continues because despite all the pharmacotherapeutic advances, the risk of recurrent ischemic complications among patients with CAD continues to be high. ${ }^{8-10}$ Vorapaxar is among one of the new classes of antiplatelet agent introduced. Vorapaxar is a protease activator receptor-1 (PAR-1) antagonist. It is the first in its class. Thrombin interacts with PAR-1 to generate fibrin formation and subsequently induces platelet aggregation. ${ }^{12,13}$ Vorapaxar was approved by the US Food and Drug Administration in May 2014 and was launched in the US for reduction in the risk of recurrent cardiovascular events and cardiovascular death and the need for revascularization in patients with previous myocardial infarction (MI) or PAD. At the time of publication, vorapaxar has not yet been launched for use in other countries (although approved in the European Union). This article reviews the role of vorapaxar in reducing cardiovascular risk.

\section{Pharmacology}

Vorapaxar is a tricyclic himbacine-derived reversible inhibitor of platelet surface PAR-1. ${ }^{14}$ Thrombin is one of the many agonists of platelet activation. Thrombin binds to PAR-1, cleaves the receptor, and allows it to bind to neighboring thrombin receptor, which subsequently leads to more platelet activation and aggregation. ${ }^{15,16}$ It is the first drug in its class to become available in the market. Although vorapaxar binds to PAR-1 reversibly, its long half-life (terminal half-life $\sim 8$ days) makes its effect essentially irreversible.

Vorapaxar is rapidly and completely absorbed after oral administration. The peak plasma concentration occurs within 1-2 hours. ${ }^{17,18}$ Food has no effect on its oral bioavailability. The mean volume of distribution of vorapaxar is $\sim 424$ L. ${ }^{16}$ Vorapaxar is primarily metabolized by CYP3A4 and CYP2J2 to an inactive metabolite (M19) and an equally potent active metabolite M20. ${ }^{16,17,19}$ Vorapaxar and M20 are extensively bound ( $\geq 99 \%$ ) to albumin. Metabolites of vorapaxar are eliminated by the kidney. There is no unchanged vorapaxar detected in urine. Vorapaxar exhibits multicompartment pharmacokinetic profile, with an effective half-life of 3-4 days and an apparent terminal elimination half-life of 8 days. Steadystate vorapaxar serum concentration is achieved by 21 days following once-daily dosing. ${ }^{16}$ Because of the metabolism by CYP3A4, the use of vorapaxar with strong CYP3A inhibitors (eg, ketoconazole, itraconazole, posaconazole, clarithromycin, nefazodone, ritonavir, to name a few) and strong CYP3A inducers (eg, rifampin) should be avoided. ${ }^{16}$ A multiple-dose drug interaction study demonstrated a doubling of steadystate $\mathrm{AUC}_{0-24 \mathrm{~h}}$ and $C_{\text {max }}$ of vorapaxar when administered with $400 \mathrm{mg}$ of ketoconazole daily, while rifampin $600 \mathrm{mg}$ daily halved $\mathrm{AUC}_{0-24 \mathrm{~h}}$ and $C_{\max }$ of vorapaxar. ${ }^{20}$

Factors such as age, race, sex, body weight $(<60 \mathrm{~kg}$ vs $\geq 60 \mathrm{~kg}$ ), moderate renal impairment (creatinine clearance $30-59 \mathrm{~mL} / \mathrm{min}$ ), and moderate hepatic impairment (Child-Pugh Class B) do not affect pharmacokinetics of vorapaxar. ${ }^{17,21}$ Since vorapaxar pharmacokinetics has not been defined in patients with severe hepatic impairment, due to the potential increased risk of bleeding in these patients, the manufacturer does not recommend its use in this patient population. $^{22}$

Vorapaxar concentrations of $5 \mathrm{mg} / \mathrm{mL}$ are necessary to achieve at least $80 \%$ blockage of thrombin receptors. Platelet function recovers after $\sim 28$ days of discontinuation of vorapaxar. ${ }^{17}$ Platelet transfusion or hemodialysis cannot reverse the antiplatelet effect of vorapaxar. ${ }^{17}$ Vorapaxar does not affect measurement of laboratory coagulation parameters. $^{23}$

\section{Clinical trials}

Two pivotal clinical trials with vorapaxar have been published to date that help to support the approval of the drug by the US Food and Drug Administration. Thrombin Receptor Antagonist for Clinical Event Reduction in Acute Coronary Syndrome (TRACER) was designed to evaluate the use of vorapaxar in ACS, and Thrombin Receptor Antagonist in Secondary Prevention of Atherothrombotic Ischemic Events - Thrombolysis in Myocardial Infarction 50 (TRA 2P-TIMI 50) was designed to evaluate the role of vorapaxar in secondary prevention of atherothrombotic events. Table 1 summarizes pertinent information on study design and results.

TRACER was a randomized, double-blinded, placebocontrolled, multicenter trial evaluating whether vorapaxar, when added to standard therapy for ACS, would improve cardiovascular end points. A total of 12,944 patients who presented within 24 hours of non-ST-segment elevation ACS and who received standard treatment, including aspirin, $\mathrm{P} 2 \mathrm{Y}_{12}$ receptor antagonist, anticoagulant, and beta-blocker, were included. ${ }^{24}$ Patients were randomized to receiving vorapaxar (40 mg loading dose followed by $2.5 \mathrm{mg}$ daily) or placebo for at least 1 year. The primary efficacy end point was the composite incidence of cardiovascular death, MI, stroke, recurrent ischemia with hospitalization, and urgent coronary revascularization. The safety end points for bleeding were assessed using the Global Use of Strategies to Open Occluded 
Table I Clinical trials of vorapaxar used in patients with cardiovascular diseases

\begin{tabular}{|c|c|c|}
\hline & $\operatorname{TRACER}^{24}(n=12,944)$ & TRA 2P-TIMI $50^{32}(n=26,449)$ \\
\hline Study design & Randomized, double blinded, controlled & Randomized, double blinded, controlled \\
\hline Intervention & $\begin{array}{l}\text { Vorapaxar } 40 \mathrm{mg} \text { loading dose followed by } 2.5 \mathrm{mg} \\
\text { daily versus placebo }\end{array}$ & Vorapaxar $2.5 \mathrm{mg}$ daily versus placebo \\
\hline $\begin{array}{l}\text { Patient } \\
\text { population }\end{array}$ & Patients presented NSTE-ACS within past 24 hours & $\begin{array}{l}\text { Patients with a history of atherosclerosis (MI or ischemic stroke within } \\
2 \text { weeks- } 12 \text { months or PAD associated with intermittent claudication and an } \\
\text { ankle brachial index }<0.85 \text { or previous revascularization for limb ischemia) }\end{array}$ \\
\hline $\begin{array}{l}\text { Primary end } \\
\text { points }\end{array}$ & $\begin{array}{l}\text { Composite of cardiovascular death, MI, stroke, } \\
\text { and recurrent ischemia with urgent coronary } \\
\text { revascularization }\end{array}$ & Composite of death from cardiovascular causes, MI, or stroke \\
\hline \multirow[t]{4}{*}{ Results } & $\begin{array}{l}\text { Primary end points: placebo } 19.9 \% \text {, vorapaxar } 18.5 \% \\
(\mathrm{HR} 0.92,95 \% \mathrm{Cl} 0.85-1.0 \mathrm{I}, \mathrm{P}=0.07)\end{array}$ & $\begin{array}{l}\text { Primary end points: placebo 10.5\%, vorapaxar } 9.3 \% \text { (HR } 0.87,95 \% \mathrm{Cl} \\
0.8-0.94, P<0.00 \mathrm{I})\end{array}$ \\
\hline & $\begin{array}{l}\text { GUSTO moderate or severe bleeding: placebo } 5.2 \% \text {, } \\
\text { vorapaxar } 7.2 \% \text { (HR I. } 35,95 \% \mathrm{Cl} \text { I.16-1.58, } P<0.05)\end{array}$ & $\begin{array}{l}\text { GUSTO moderate or severe bleeding: placebo } 2.5 \% \text {, vorapaxar } 4.2 \% \text { (HR } \\
\text { I. } 66,95 \% \mathrm{Cl} I .43-1.93, P<0.05)\end{array}$ \\
\hline & $\begin{array}{l}\text { Clinically significant TIMI bleeding: placebo } 14.6 \% \text {, } \\
\text { vorapaxar } 20.2 \% \text { (HR I. } 43,95 \% \mathrm{CI} I .3 \mathrm{I}-\mathrm{I} .57, P<0.05)\end{array}$ & $\begin{array}{l}\text { Clinically significant TIMI bleeding: placebo } 0.5 \% \text {, vorapaxar I\% (HR I.94, } \\
95 \% \mathrm{Cl} \text { I.39-2.70, } P<0.05 \text { ) }\end{array}$ \\
\hline & $\begin{array}{l}\mathrm{ICH}: \text { placebo } 0.2 \% \text {, vorapaxar I. } 1 \%(\mathrm{HR} 3.39,95 \% \mathrm{Cl} \\
\text { I.78-6.48, } P<0.05)\end{array}$ & ICH: placebo $0.5 \%$, vorapaxar I\% (HR I.94, 95\% Cl I.39-2.70, $P<0.00 \mathrm{I})$ \\
\hline
\end{tabular}

Notes: $P$-values calculated using Cox proportional-hazards model.

Abbreviations: TRACER, Thrombin Receptor Antagonist for Clinical Event Reduction in Acute Coronary Syndrome; TRA 2P-TIMI 50, Thrombin Receptor Antagonist in Secondary Prevention of Atherothrombotic Ischemic Events - Thrombolysis in Myocardial Infarction 50; NSTE-ACS, Non-ST-segment elevation acute coronary syndrome; MI, myocardial infarction; PAD, peripheral arterial disease; HR, hazard ratio; Cl, confidence interval; GUSTO, Global Use of Strategies to Open Occluded Arteries; TIMI, thrombolysis in myocardial infarction; $\mathrm{ICH}$, intracranial hemorrhage.

Arteries (GUSTO) and Thrombolysis in Myocardial Infarction (TIMI) classification systems. ${ }^{25}$

For the primary end point, composite events occurred in $18.5 \%$ of patients receiving vorapaxar versus $19.9 \%$ of patients receiving placebo $(P=0.07)$. Rates of the major safety end point, GUSTO moderate or severe bleeding, were increased by $35 \%$ compared to placebo, and clinically significant TIMI bleeding was increased by $43 \%$. Intracranial hemorrhage $(\mathrm{ICH})$ occurred in $1.1 \%$ of patients with vorapaxar compared to $0.2 \%$ with placebo $(P<0.001)$. This significant increase in ICH led to early termination of the trial. Subgroup analysis showed higher rates of GUSTO moderate or severe bleeding in patients with lower body weight $(P=0.03)$.

In a subanalysis of 4,194 patients managed medically (including those who underwent angiography but without interventions), event rates for primary outcomes were $16.3 \%$ with vorapaxar and $17.0 \%$ with placebo (hazard ratio [HR] $0.99,95 \%$ confidence interval [CI] 0.83-1.17). Vorapaxar increased GUSTO moderate or severe bleeding numerically in medically managed patients (adjusted HR 1.46, 95\% CI 0.99-2.15). This is consistent with the whole population. ${ }^{26}$ Similarly, in another subanalysis of patients who underwent PCI, the efficacy and bleeding are consistent with the overall population. ${ }^{27}$ Whether glycoprotein IIb/IIIa receptor inhibitors were used during PCI did not affect the outcome. ${ }^{28}$ In contrary, in another subanalysis evaluating 1,312 patients with non-ST-segment elevation ACS undergoing coronary arterial bypass graft (CABG) surgery, vorapaxar was asso- ciated with a significant reduction in ischemic events $(45 \%$ lower) and no significant increase in major CABG surgeryrelated bleeding. Because the number of patients undergoing CABG surgery is small, randomized trials are needed to confirm the observation. ${ }^{29}$ In another subanalysis of $936(7.2 \%)$ patients who had a history of PAD, the rates of primary end points were similar between vorapaxar and placebo $(21.7 \%$ vs $24.8 \%, P$ interaction $=0.787$ ).

A separate analysis examined the impact of DAPT on vorapaxar bleeding risk. Approximately 87\% $(11,307)$ of patients in TRACER were receiving DAPT, with the vast majority receiving aspirin plus clopidogrel. ${ }^{30}$ The use of DAPT was associated with increased bleeding risk when vorapaxar was added. The impact of aspirin dose was also evaluated. Whether the patients were receiving $\leq 100 \mathrm{mg}$ or $\geq 300 \mathrm{mg}$ aspirin had no impact on the risk of bleeding (adjusted HR for GUSTO severe bleeding: 1.88 vs $1.63, P=0.954){ }^{31}$

The TRA 2P-TIMI 50 is a Phase III clinical trial designed to evaluate the use of vorapaxar for secondary prevention of atherothrombosis. ${ }^{32}$ Patients with a previous history of MI or ischemic stroke within the previous 2 weeks-12 months or PAD were randomized to receive vorapaxar $2.5 \mathrm{mg}$ daily or placebo. The primary efficacy end point was the composite of cardiovascular death, MI, and stroke.

After a median follow-up of 24 months, the protocol was amended to exclude patients with a history of stroke due to an increased risk of $\mathrm{ICH}$ in these patients, by 2.5 -fold (vorapaxar $2.5 \%$ vs placebo $1 \%, P<0.001)$. For the primary end 
point, composite events occurred in $9.3 \%$ patients receiving vorapaxar versus $10.5 \%$ patients receiving placebo $(P<0.001)$. Safety in TRA 2P-TIMI 50 was also evaluated using GUSTO moderate or severe bleeding criteria and TIMI bleeding criteria. In the whole population, there was significantly more bleeding in those receiving vorapaxar $(4.2 \%$ of patients who received vorapaxar vs $2.5 \%$ of those who received placebo; HR $1.66,95 \%$ CI $1.43-1.93, P<0.001)$. There was an increase in the rate of ICH in the vorapaxar group $(1.0 \%$ vs $0.5 \%$ in the placebo group, $P<0.001)$. A composite primary efficacy and GUSTO moderate or severe bleeding safety end points (net clinical benefit) showed no significant difference between placebo and vorapaxar. The additional clinical benefit provided by vorapaxar appeared to have been offset by the bleeding risk. The net clinical outcome was $11.7 \%$ in the vorapaxar group and $12.1 \%$ in the placebo group $(P=0.40)$.

A subanalysis was done for the 3,787 patients with a history of PAD..$^{33}$ One-third of them were on a thienopyridine, $11 \%$ on cilostazol, and $88 \%$ on aspirin for PAD management. Similar to the rest of the cohort, vorapaxar did not reduce incidence of primary end point (vorapaxar $11.3 \%$ vs placebo $11.9 \%, P=0.53$ ). Vorapaxar, however, significantly reduced ischemic events in the limbs (vorapaxar $2.3 \%$ vs placebo $3.9 \%, P=0.006$ ) and the need for peripheral artery revascularization (vorapaxar $18.4 \%$ vs placebo $22.2 \%$, $P=0.017)$.

Another prespecified subgroup analysis examined 17,779 patients who were enrolled due to past history of MI. ${ }^{34}$ In all, $98 \%$ of patients received aspirin and $78 \%$ received thienopyridine at enrollment. Vorapaxar significantly reduced primary end points as compared to placebo (vorapaxar $8.1 \%$ vs placebo $9.7 \%, P<0.0001)$. Specifically examining those patients who had a previous MI and also diabetes $(n=3,623)$, vorapaxar significantly reduced the primary end point (vorapaxar $11.4 \%$ vs placebo $14.3 \%$, HR $0.73,95 \%$ CI $0.60-0.89$, $P=0.002) .{ }^{35}$ In all these patient subgroups, bleeding increased with vorapaxar use as compared to placebo, similar to the rest of the cohort.

In the overall TRA 2P-TIMI 50 trial, $\sim 58 \%(15,356)$ of patients were also concurrently on thienopyridine and $94 \%$ $(24,734)$ received aspirin. The use of thienopyridine had no impact on the risk of GUSTO moderate or severe bleeding. ${ }^{36}$ A substudy that evaluated the impact of aspirin dose also reported no differences in moderate or severe bleeding in those receiving low $(<100 \mathrm{mg})$, moderate $(100-162 \mathrm{mg})$, or high aspirin doses $(>162 \mathrm{mg}) \cdot{ }^{37}$ The number of patients receiving high-dose aspirin was small (16\%); thus, a firm conclusion cannot be made.

\section{Adverse events}

Besides bleeding, based on combined results from TRACER and TRA 2P-TIMI 50, anemia, depression, and exanthems are some of the most commonly reported side effects, which occurred in $5 \%, 2.4 \%$, and $2.2 \%$ of patients, respectively. ${ }^{16}$

Patients being considered for vorapaxar should be carefully assessed for overall bleeding risk versus cardiovascular benefits. Risk factors that can increase bleeding include older age, low body weight, reduced renal or hepatic function, history of bleeding disorders, and use of certain concomitant medications (eg, anticoagulants, fibrinolytics, nonsteroidal anti-inflammatory drugs). Vorapaxar is contraindicated in patients with a history of stroke, transient ischemic attack, or ICH. Currently, there is no antidote for vorapaxar. ${ }^{16}$ Although the current data suggest that vorapaxar may be safely used perioperatively in patients undergoing PCI or CABG surgery, the number of patients in the vorapaxar studies undergoing these procedures is small and further risk evaluation is necessary.

\section{Dosage and administration}

Vorapaxar has been approved for use in patients with a history of MI and PAD in the US to reduce cardiovascular events. ${ }^{16}$ The drug is available as $2.5 \mathrm{mg}$ vorapaxar sulfate film-coated tablets (contains $2.08 \mathrm{mg}$ of vorapaxar). The recommended dose is one tablet daily. ${ }^{16,38}$ Vorapaxar can be used with aspirin and/or clopidogrel based on standards of care. ${ }^{16}$ There is a lack of clinical data in use of vorapaxar with other antiplatelet drugs or as monotherapy.

Renal impairment or mild-to-moderate hepatic impairment (Child-Pugh Class A or B) does not require dosage adjustment when using vorapaxar. ${ }^{16,20}$ In patients with severe hepatic impairment (Child-Pugh Class C), vorapaxar use should be avoided. ${ }^{16,21}$ Vorapaxar is contraindicated in patients with a history of stroke, transient ischemic attack, $\mathrm{ICH}$, or active bleeding. ${ }^{16}$

\section{Therapeutic role}

Because the risk of recurrent ischemic complications among patients with established CAD continues to be high, newer antithrombotic agents continue to be developed with an aim to further optimize the risk. Vorapaxar, when used in patients with cardiovascular diseases who were receiving standard therapy, reduced the risk of cardiovascular events. However, such benefits came with increased risk of bleeding, which appeared to offset the benefits. The use of vorapaxar has not been incorporated into any treatment guidelines to date. 
The decision in using vorapaxar should be based on careful balance of individual patients' bleeding risk and the further cardiovascular benefits that they may get. If patients experienced recurrent ischemic events despite optimal standard of therapy, then vorapaxar should be considered with close monitoring of bleeding complications.

\section{Conclusion}

Vorapaxar is a selective and competitive PAR-1 antagonist that inhibits thrombin-induced platelet aggregation. In patients with recent ACS, vorapaxar, when added to standard therapy, did not reduce the composite cardiovascular end point. In contrary, in a study of secondary prevention for patients with cardiovascular diseases, vorapaxar reduced the risk of cardiovascular death or ischemic events (MI, stroke) in patients with stable atherosclerosis who were receiving standard therapy. Vorapaxar is approved in the US for use with aspirin and/or clopidogrel in the secondary prevention of thrombogenic cardiovascular events in stable patients with PAD or a history of MI. Vorapaxar increases risk of bleeding. The manufacturer and the US Food and Drug Administration both indicated that the use in individuals who have an increase in bleeding risk, including elderly patients and patients with low body weight, requires caution. ${ }^{16,39,40}$ It is essential to balance individual patient's bleeding risk to any further cardiovascular benefits that they may get. Future investigation is also needed to evaluate the use of vorapaxar with newer antiplatelet agents such as ticagrelor or cangrelor, as well as its role as monotherapy.

\section{Disclosure}

The author reports no conflicts of interest in this work.

\section{References}

1. Go AS, Mozaffarian D, Roger V, et al; American Heart Association Statistics Committee and Stroke Statistics Subcommittee. Heart disease and stroke statistics - 2014 update: a report from the American Heart Association. Circulation. 2014;129(3):e28-e292.

2. Davì G, Patrono C. Platelet activation and atherothrombosis. $N$ Engl J Med. 2007;357(24):2482-2494.

3. Circulation [webpage on the Internet]. 2014 AHA/ACC Guidelines for the Management of Patients with Non-ST Elevation Acute Coronary Syndrome: A Report of the American College of Cardiology Foundation/American Heart association Task Force on Practice Guidelines. Available from: http://circ.ahajournals.org/content/early/2014/09/22/ CIR.0000000000000133. Accessed October 7, 2014.

4. O'Gara PT, Kushner FG, Ascheim DD, et al. 2013 ACCF/AHA guideline for the management of ST elevation myocardial infarction. Circulation. 2013;127:e362-e425.

5. Yusuf S, Zhao F, Mehta SR, et al; Clopidogrel in Unstable Angina to Prevent Recurrent Events Trial Investigators. Effects of clopidogrel in addition to aspirin in patients with acute coronary syndromes without ST-segment elevation. N Engl J Med. 2001;345(7):494-502.
6. Mehta SR, Yusuf S, Peters RJ, et al; Clopidogrel in Unstable angina to prevent Recurrent Events trial (CURE) Investigators. Effects of pretreatment with clopidogrel and aspirin followed by long-term therapy in patients undergoing percutaneous coronary intervention: the PCI-CURE study. Lancet. 2001;358(9281):527-533.

7. Sabatine MS, Cannon CP, Gibson CM, et al; CLARITY-TIMI 28 Investigators. Addition of clopidogrel to aspirin and fibrinolytic therapy for myocardial infarction with ST-segment elevation. $N$ Engl J Med. 2005;352(12):1179-1189.

8. Mega JL, Close SL, Wiviott SD, et al. Cytochrome P450 genetic polymorphisms and the response to prasugrel relationship to pharmacokinetics, pharmacodynamic, and clinical outcomes. Circulation. 2009;119(19):2553-2560.

9. Wiviott SD, Braunwald E, McCabe $\mathrm{CH}$, et al. Prasugrel versus clopidogrel in patients with acute coronary syndrome. $N$ Engl J Med. 2007;357(20):2001-2015.

10. Wallentin L, Richard BC, Budaj A, et al. Ticagrelor versus clopidogrel in patients with acute coronary syndromes. $N$ Engl J Med. 2009;361(11):1045-1057.

11. Bhatt DL, Stone GW, Mahaffey KW, et al. Effect of antiplatelet inhibitor with cangrelor during PCI on ischemic events. N Engl J Med. 2013;368(14):1303-1313.

12. Chackalamannil S, Xia Y, Greenlee WJ, et al. Discovery of potent orally active thrombin receptor (protease activated receptor 1) antagonists as novel antithrombotic agents. J Med Chem . 2005;48(19):5884-5887.

13. Chackalamannil S. Thrombin receptor (protease activated receptor-1) antagonists as potent antithrombotic agents with strong antiplatelet effects. J Med Chem. 2006;49(18):5389-5403.

14. Chackalamannil S, Wang Y, Greenlee WJ, et al. Discovery of a noval, orally active himbacine-based thrombin receptor antagonist (SCH530348) with potent antiplatelet activity. J Med Chem. 2008;51(11):3061-3064.

15. Angiolillo D, Capranzano P. Pharmacology of emerging novel platelet inhibitors. Am Heart J. 2008;156(2):10S-15S.

16. Merck [webpage on the Internet]. Zontivity ${ }^{\mathrm{TM}}$ [prescribing information]. Available from: http://www.merck.com/product/usa/pi_circulars/z/ zontivity/zontivity_pi.pdf. Accessed October 10, 2014.

17. FDA [webpage on the Internet]. FDA Briefing Document. Cardiovascular and Renal Advisory Committee; 2014. Available from: http://www. fda.gov/downloads/advisorycommittees/committeesmeetingmaterials/ drugs/cardiovascularandrenaldrugsadvisorycommittee/ucm381327.pdf. Accessed November 13, 2014.

18. Behm MO, Kosoglou T, Miltenburg AMM, et al. The absence of a clinically significant effect of food on the single dose pharmacokinetics of vorapaxar, a PAR-1 antagonist, in healthy adult subjects. Clin Pharmacol Drug Dev. 2013;2(4):310-315.

19. Ghosal A, Lu X, Penner N, et al. Identification of human liver cytochrome P450 enzymes involved in the metabolism of SCH 530348 (vorapaxar), a potent oral thrombin protease-activated receptor 1 antagonist. Drug Metab Dispos. 2011;39(1):30-38.

20. Kosoglou T, Statkevich P, Kumar B, et al. The effect of multiple doses of ketoconazole or rifampin on the single- and multiple dose pharmacokinetics of vorapaxar. J Clin Pharmacol. 2013;53(5):540-549.

21. Kosoglou T, Kraft WK, Kumar B, et al. Pharmacokinetics and pharmacodynamics of the novel PAR-1 antagonist vorapaxar in patients with end-stage renal disease. Eur J Clin Pharmacol. 2012;68(7):1049-1056.

22. Statkevich P, Kosoglou T, Preston RA, et al. Pharmacokinetics of the novel PAR-1 antagonist vorapaxar in patients with hepatic impairment. Eur J Clin Pharmacol. 2012;68(11):1501-1508.

23. Chintala M, Shimizu K, Ogawa M, Yamaguchi H, Doi M, Jensen P. Basic and translational research on proteinase-activated receptors: antagonism of the proteinase-activated receptor 1 for thrombin, a novel approach to antiplatelet therapy for atherothrombotic disease. J Pharmacol Sci. 2008;108(4):433-438.

24. Tricoci P, Huang Z, Held C, et al; TRACER Investigators. Thrombin receptor antagonist vorapaxar in acute coronary syndromes. $N$ Engl J Med. 2012;366(1):20-33. 
25. Kikkert WJ, van Geloven N, van der Laan $\mathrm{MH}$, et al. The prognostic value of bleeding academic research consortium (BARC)-defined bleeding complications in ST segment elevation myocardial infarction: a comparison with the TIMI, GUSTO and ISTH bleeding classification. J Am Coll Cardiol. 2014;63(18):1866-1875.

26. Held C, Tricoci P, Huang Z, et al. Vorapaxar, a platelet thrombin receptor antagonist, in medically managed patients with non-ST segment elevation acute coronary syndrome: results from the TRACER trial. Eur Heart J Acute Cardiovasc Care. 2014;3(3):246-256.

27. Valgimigli M, Tricoci P, Huang Z, et al. Usefulness and safety of vorapaxar in patients with non-ST segment elevation acute coronary syndrome undergoing percutaneous coronary intervention (from the TRACER trial). Am J Cardiol. 2014;114(5):665-673.

28. Cornel JH, Tricoci P, Lokhngina Y, et al. Glycoprotein IIb/IIIa receptor inhibitors in combination with vorapaxar, a platelet thrombin receptor antagonist, among patients with non-ST-segment elevation acute coronary syndromes (from the TRACER trial). Am J Cardiol. 2015;115(10):1325-1332.

29. Whellan DJ, Tricoci P, Chen E, et al. Vorapaxar in acute coronary syndrome patients undergoing coronary artery bypass graft surgery: subgroup analysis from the TRACER trial (thrombin receptor antagonist for clinical event reduction in acute coronary syndrome). J Am Coll Cardiol. 2014;63(11):1048-1057.

30. Tricoci P, Huang Z, van de Werf F, et al. Vorapaxar with and without thienopyridine use in acute coronary syndromes: results from the TRACER trial. Eur Heart J. 2012;33:495-496.

31. Mahaffey KW, Huang Z, Wallentin L, et al. Association of aspirin dose and vorapaxar safety and efficacy in patients with non-ST-segment elevation acute coronary syndrome (from the TRACER Trial). Am J Cardiol. 2014;113(6):936-944.

32. Morrow DA, Braunwald E, Bonaca MP, et al; TRA 2P-TIMI 50 Steering Committee and Investigators. Vorapaxar in the secondary prevention of atherothrombotic events. $N$ Engl J Med. 2012;366(15):1404-1413.
33. Bonaca MP, Scirica BM, Creager MA, et al. Vorapaxar in patients with peripheral artery disease. Results from TRA 2P-TIMI 50. Circulation. 2013;127(14):1522-1529.

34. Scirica BM, Bonaca MP, Braunwald E, et al. Vorapaxar for secondary prevention of thrombotic events for patients with previous myocardial infarction: a prespecified subgroup analysis of the TRA 2P-TIMI 50 trial. Lancet. 2012;380(9850):1317-1324.

35. Cavender MA, Scirica BM, Bonaca MP, et al. Vorapaxar in patients with diabetes mellitus and previous myocardial infarction: findings from the thrombin receptor antagonist in secondary prevention of atherothrombotic ischemic events - TIMI 50 trial. Circulation. 2015;131(12):1047-1053

36. Bohula EA, Aylward PE, Bonaca MP, et al. Efficacy and safety of vorapaxar with and without a thienopyridine for secondary prevention in patients with previous myocardial infarction and no history of stroke or transient ischemic attack: results from TRA $2^{\circ} \mathrm{P}-\mathrm{TIMI} 50$. Circulation. 2015;132(20):1871-1879.

37. Scirica BM, Bonaca MP, Braunwald E, et al. Vorapaxar for secondary prevention after myocardial infarction according to aspirin dose insights from the TRA 2P-TIMI 50 trial. Circulation. 2012;126: A14508.

38. Kosoglou T, Reyderman L, Tseng J, et al. Effect of food, antacid, and age on the pharmacokinetics of the oral thrombin receptor antagonist vorapaxar (sch 530348) in healthy volunteers. Clin Pharmacol Drug Dev. 2013;2(3):223-230.

39. Baker NV, Lipinski MJ, Lhermusier T, Waksman R. Overview of the 2014 food and drug administration cardiovascular and renal drugs advisory committee meeting about vorapaxar. Circulation. 2014;130(15):1287-1294.

40. Pisters R, Lane DA, Nieuwlaat R, de Vos CB, Crijns HJ, Lip GY. A novel user-friendly score (HAS-BLED) to assess 1-year risk of major bleeding in patients with atrial fibrillation: the euro heart survey. Chest. 2010;138(5):1093-1100.
Vascular Health and Risk Management

\section{Publish your work in this journal}

Vascular Health and Risk Management is an international, peerreviewed journal of therapeutics and risk management, focusing on concise rapid reporting of clinical studies on the processes involved in the maintenance of vascular health; the monitoring, prevention and treatment of vascular disease and its sequelae; and the involvement of

\section{Dovepress}

metabolic disorders, particularly diabetes. This journal is indexed on PubMed Central and MedLine. The manuscript management system is completely online and includes a very quick and fair peer-review system, which is all easy to use. Visit http://www.dovepress.com/ testimonials.php to read real quotes from published authors. 